\title{
ATRIAL FIBRILLATION DUE TO ORAL METHYLPREDNISOLONE IN A PATIENT WITH MEMBRANOPROLIFERATIVE GLOMERULONEPHRITIS
}

\author{
Ayhan Dogukan', Erdogan Ilkay', Orhan K. Poyrazoglu', Ali Ihsan Gunal ${ }^{1}$, Metin Ozgen ${ }^{1}$, Murat Pekdemir ${ }^{3}$ \\ Firat University, Faculty of Medicine, Elazig, Turkey: Department of Nephrology ${ }^{1}$, Department of Cardiology ${ }^{2}$, Department \\ of Emergency Medicine ${ }^{3}$ \\ Summary: Cardiac adverse effects of intravenous pulse methylprednisolone administration are well known, but there is little \\ information about the cardiac side effects of oral methylprednisolone in the literature. We present a 41 year-old man with \\ membranoproliferative glomerulonephritis in whom developed atrial fibrillation after oral methylprednisolone therapy.
}

Key words: Atrial fibrillation; Oral methylprednisolone

\section{Introduction}

Glucocorticoids are widely used for the treatment of glomerulonephritis, vasculitis, and collagen tissue disorders because of their antiinflammatory and immune altering properties. Although the side effects of glucocorticoids are generally well known, only a few articles have been published about their side effects on the cardiovascular system. Despite the fact that atrial fibrillation (AF), ischemic electrocardiographic changes, bundle branch block with supraventricular tachycardia (SVT), severe bradycardia, and sudden death have been reported as results of intravenous (iv) pulse application of methylprednizolone (MPZ) (2, 6, $7,8,10$ ), a short acting glucocorticoid agent, only two case reports about oral MPZ using as a possible cause of cardiac side effects have been found $(3,4)$.

Therefore, we report a patient with membranoproliferative glomerulonephritis who developed AF after oral MPZ treatment.

\section{Case}

A 41 year-old man presented with pretibial edema and general weakness. He didn't have any other comorbidities (hypertension, cardiac disease, etc.). On examination, his heart rate was 82 beats/min regularly, blood pressure was 150/100 mm Hg. The laboratory values were obtained: blood urea nitrogen $92 \mathrm{mg} / \mathrm{dl}$; creatinine $2.7 \mathrm{mg} / \mathrm{dl}$; potassium 4.7 $\mathrm{mEq} / \mathrm{L}$. Urinalysis was included: 10-15 erythrocytes; 4-5 leukocytes; $2+$ proteinuria. Renal biopsy was done because of hematuria, proteinuria, and renal dysfunction. The results of the renal biopsy proved that the patient had mem- branoproliferative glomerulonephritis. After the diagnosis was achieved, treatment was initiated with oral fluocortolone $(75 \mathrm{mg} / \mathrm{d})$, which is also a short acting glucocorticoid agent, acetylsalicylic acide $(100 \mathrm{mg} / \mathrm{d})$, furosemide (40 $\mathrm{mg} / \mathrm{d})$, quinapril $(10 \mathrm{mg} / \mathrm{d})$. Six weeks after this treatment, we changed fluocortolone for oral MPZ (48 mg/d) because of the transient lack of it in the markets. On the second day of this therapy, he presented with palpitation and mild chest pain. The findings on the physical examination revealed the following: his blood pressure was $130 / 80 \mathrm{mmHg}$ and pulse was 110 beats/min and irregular. Physical examination showed no murmurs, rubs, or gallops, but an irregular heartbeat. The remainder of the physical examination was normal. His hemoglobin was $11.9 \mathrm{~g} / \mathrm{dl}$ and the white blood cell count was $18000 / \mathrm{mm} 3$. The following laboratory findings were included: blood urea nitrogen $80 \mathrm{mg} / \mathrm{dl}$; creatinine $2.4 \mathrm{mg} / \mathrm{dl}$; sodium $131 \mathrm{mEq} / \mathrm{L}$; potassium 5.2 $\mathrm{mEq} / \mathrm{L}$; albumin $4.4 \mathrm{~g} / \mathrm{dl}$; calcium $9.7 \mathrm{mg} / \mathrm{dl}$; total cholesterol $292 \mathrm{mg} / \mathrm{dl}$; triglyceride $235 \mathrm{mg} / \mathrm{dl}$. Urinalysis findings were 3-5 erythrocytes, 3-5 leukocytes, 1+ proteinuria. AF was defined as a rate of 100-130 beats/min on the electrocardiogram. Creatine phosphokinase $(\mathrm{CK})$ and CK-MB levels were normal. Troponin $\mathrm{T}$ was negative. Thyroid hormone levels were normal. A fundoscopic examination showed grade I hypertensive retinopathy. Mild left ventricular hypertrophy was ascertained by bedside echocardiographic examination, but no pericardial fluid was present. At elective echocardiography, left atrial size was $33 \mathrm{~mm}$, interventricular septum thickness $8 \mathrm{~mm}$, and left ventricular posterior wall $9 \mathrm{~mm}$. Tallium sintigraphy was normal. At the clinical follow-up, we did not observed hypertension or electrolyte imbalance. 
After metoprolol (1 mg), a beta blocker agent, was given intravenously to the patient, arrhythmia recovered to sinus rhythm and pulse rate was decreased to 94 beats/min. Unfortunately, AF repeated approximately 2 hours later. Metoprolol was applied again until the rhythm was regulated. Afterwards, the beta blocker therapy was continued with oral atenolol ( $25 \mathrm{mg} / \mathrm{d})$. Three days later, AF occured again and was treated with metoprolol as above. Oral MPZ treatment was finished because we suspected that AF could be a possible adverse reaction to this drug, and we restarted fluocortolone treatment. Atenolol was gradually discontinued in the following four weeks. No symptomatic AF episode occurred during the following five months. Other treatments were not changed.

\section{Discussion}

In our patient, AF occrured on the second day of MPZ treatment and reoccurred on the fifth day of the drug administration. After returning to fluocortolone, AF did not occur over the course of the following five months. We didn't determine any other pathology contributing to AF out of MPZ treatment. Althought he had mild hypertension on his history, he was normotensive during the two episodes of atrial fibrillation. In a report, MPZ was accused of marked bradycardia in a 14 -year-old patient with rapidly progressive glomerulonephritis after using both iv and oral form of MPZ, consecutively (4). They suggested that a high dose of oral or iv application of MPZ may cause adverse effect on the cardiovascular system. In addition, Lucas et al. pointed out that the speed of administration could be an important factor for this situation (5). In another article, a patient who had paroxysmal atrial tachycardia attacks that could have been with vagal maneuvers for the last 35 years was reported. Oral MPZ $(30 \mathrm{mg})$ was started for reatment of his acute shoulder pain. During the second day of medication, SVT that didn't respond to vagal maneuver occured and then AF followed. AF was recovered after the patient swallowed $20 \mathrm{mg}$ of nadolol and discontinued the methylprednisolone. During the following six years, AF was not observed, inspite of SVT attacks (3). However, it is interesting that pulse MPZ was not applied to our patient and he didn't have underlying rhythm disorders as described in the above two cases. In addition, we only exchanged fluo- cortolone for oral MPZ during a therapy program continuing without any problem.

It was postulated that MPZ mediates calcium and potassium flux across cell membranes $(1,4)$. The linkage of corticosteroids and arrhythmia via potassium efflux seems a sufficient explanation for the effects of high dose pulse therapy $(6,7,8,10)$. Although hypokalemia (8), underlying rhythm disorders (3), and severe pain (9) are the predisposing factors thought to cause arrhythmia, none of these circumstances was found in our patient. However, it is not enough to explain the possible mechanism between lower dose oral MPZ administration and AF in our patient because the potassium serum concentrations are within normal limits (4.5-5.2 meq/L). Also, we could not explain why the fibrillation appeared after methylprednisolon administration and not during the previous therapy with fluocortolon.

In conclusion, although the predisposing factors reported previously were not in our patient, MPZ might cause cardiac problems through undefined mechanisms. Physicians should keep in mind that even low dose of oral MPZ could contribute to atrial fibrillation.

\section{References}

1. Fujimoto S, Kundoh H, Yamamoto H, Hisanaga S, Tanaka K. Holter electrocardiogram monitoring in nephritic patients during methylprednisolone pulse therapy. Am J Nephrol 1990;10:231-36.

2. Gardnier PVG, Griffiths TD: Sudden death after treatment with pulsed methylprednisolone. Br Med J 1990;300:125

3. Juni S, Kerstein M. Atrial fibrillation induced by oral methylprednisolone J Pharm Technol 2002;18:16-9.

4. Kucukosmanoglu O, Karabay A, Ozbarlas N, Noyan A, Anarat A. Marked bradycardia due to pulsed and oral methylprednisolone therapy in a patient with rapidly progressive glomerulonephritis. Nephron 1998;80:484.

5. Lucas KG, Howrie DL, Carol KP. Cardiorespiratory decompensation following methylprednisolone administration. Pediatr Hematol Oncol 1993;10:249-55.

6. McDermott MF, Nasr I, Rydman RJ, Cordero M, Kampe LM, Lewis R et al. Comparison of two regimens of beta-adrenergic in acute asthma. J Med Syst 1999;23:269-79.

7. McLukie A, Savage RW. Atrial fibrillation following methylprednisolone pulse therapy in an adult. Chest 1993;104:623-4

8. Moretti R, Torre RM, Antonello M, Zorzon M, Cazzato G. Recurrent atrial fibrillation with pulse administration of high doses of methylprednisolone: a possible prophylactic treatment. Eur J Neurol 2000;7:130.

9. Nastri MV, Taricco MA, Alves VAF, Mansur AJ. Paroxysmal atrial fibrillation and insidious neck pain. Clin Cardiol 2000;23:219-20.

10. Rozenthal JM, Robbins HI, Finlay J, Healy B, Levin AB, Steeves RA et al. "Eightdrugs-in-one-day" chemotherapy administered before and after radiotherapy to adult patients with malignant gliomas. Cancer 1989;63:2475-81.

Submitted September 2007. Accepted January 2008.

\section{Corresponding author:}

Ayhan Dogukan, M.D., Firat University Medical Faculty, Nephrology Unit, 23119, Elazig, Turkey, e-mail: aydogukan@hotmail.com 